\section{BUCKLING OF THE OCEANIC LITHOSPHERE FROM GEOPHYSICAL DATA AND EXPERIMENTS}

Jonathan M. Bull

Department of Geology, University of Southampton, Southampton, United Kingdom

Joseph Martinod ${ }^{\mathfrak{l}}$ and Philippe Davy

Institut de Geologie, Campus de Beaulieu, Rennes, France

\begin{abstract}
Two major hypotheses have been advanced for the formation of the long wavelength $(100-300 \mathrm{~km})$ undulations of oceanic basement and overlying sediments developed in the central Indian Ocean basin: whole layer folding (buckling) and local thickening (inverse boudinage). Using appropriately scaled two-layer analogue models for the oceanic lithosphere comprising a brittle layer above a ductile layer, we show that buckling of the entire brittle layer is likely to be the mode of deformation. However, the lithosphere-asthenosphere boundary remains undisturbed. We find a relationship between the thickness of the brittle layer and the wavelength of folding such that the wavelength is 7 times the brittle layer thickness.
\end{abstract}

\section{INTRODUCTION}

The intraplate deformation in the northern Indian Ocean is now well documented from geophysical data [Weissel et al., 1980; Geller et al., 1983; Neprochnov et al., 1988; Bergman and Solomon, 1985; Bull and Scrutton, 1990a] and has been explained in terms of a diffuse plate boundary between the Indian and Australian plates [Demets et al., 1988; Petroy and Weins, 1989; Gordon et al., 1990; Royer and Chang, 1991]. The deformation, although dominantly compressive, also has a strike-slip component as demonstrated by the offset of longwavelength features across fracture zones (Figure 1) (see also Bull [1990a]) and the occurrence of strike-slip as well as dip-slip earthquakes [Bergman and Solomon, 1985; Petroy and Wiens, 1989].

Although the style of deformation is well documented, there is still uncertainty as to the mode of instability that has facilitated the formation of the long-wavelength (100$300 \mathrm{~km}$ ) undulations in this area. Two major hypotheses have been proposed for the formation of the longwavelength undulations: buckling and inverse boudinage [Zuber, 1987]. The first of these deformation modes, buckling, is characterized by uniform layer folding without substantial thickness variations and is usually associated with a relatively strong layer deforming under compression. Inverse boudinage, on the other hand, is the result of pinch and swell instability growing in a layer less competent than the surrounding layers [Smith, 1977].

\footnotetext{
${ }^{1}$ Now at Observatoire de Grenoble, Grenoble, France.
}

Copyright 1992 by the American Geophysical Union.

Paper number 91TC02908.

0278-7407/92/91TC-02908\$10.00
While the oceanic lithosphere is never softer than its surrounding layers, some authors [e.g., Zuber, 1987] think that inverse boudinage might be the main deformation mode during compression if the lithosphere is not very strong, and if gravity plays an important role. Although some authors have discussed the amplification of periodic instabilities (buckling and inverse boudinage for example) as a deformation mechanism for the oceanic lithosphere [Zuber, 1987; Stephenson and Cloetingh, 1991], there is still considerable uncertainty as to the modes of periodic instabilities and their relationships with lithospheric rheologies. In this paper we describe eight analogue experiments using the sandbox technique to clarify the development of periodic instabilities under compression and their relationships with faulting. We use an appropriately scaled two-layer, brittle-viscous rheology to represent the oceanic lithosphere.

\section{INTRAPLATE DEFORMATION}

In the northern Indian Ocean (Figure 1) the intraplate deformation is characterized by a diffuse zone of large magnitude seismicity [Bergman and Solomon, 1985; Petroy and Weins, 1989], localized high heat flow [Stein and Weissel, 1990], and gravity and geoid anomalies [Stein et al., 1989] as well as by tectonic deformation [Weissel et al., 1980; Geller et al., 1983; Neprochnov et al., 1988; Bull, 1990a; Bull and Scrutton, 1990a].

Ocean Drilling Program leg 116 [Shipboard Scientific Party, 1989] drilled two fault blocks within the deformation area and found that the onset of deformation was marked by an unconformity at $7 \mathrm{Ma}$. The faults appear to have been active since the onset of the deformation [Shipboard Scientific Party, 1989]. It is unclear if the unconformity marking the onset of deformation, which can be seen on seismic profiles through much of the deformation area, is diachronous over the $\sim 1500 \mathrm{~km}$ north-south spatial extent of the deformation [Curray and Munasingbe, 1989]. However, it seems likely that the fault movement and undulation development were synchronous.

The tectonic deformation occurs on two spatial scales (Figure 2). First, there are long-wavelength $(100-300 \mathrm{~km})$ undulations of oceanic basement and overlying sediments. Second, there are shorter-wavelength $(5-10 \mathrm{~km})$ reverse faults and associated folds, the former penetrating throughout the deforming oceanic crust [Bull and Scrutton, 1990a]. The folds associated with these reverse faults occur in the hanging walls of reverse faults and appear on multichannel profiles to be limited to the sedimentary cover [Bull and Scrutton, 1990a]. Bull [1990a] concluded that the shorter wavelength phenomena had modified the longer wavelength, with some accentuation of the crests relative to the troughs, but that faulting alone could not have produced the observed long wavelength topography. There is an underlying flexural mechanism. The nature of the relationship between the two spatial scales of deformation will be discussed later in this paper.

Gordon et al. [1990], from inversion of present-day spreading rates and directions of plate boundaries in the Indian Ocean, suggested a shortening rate of 1-7 mm $\mathrm{yr}^{-1}$ in the central Indian Ocean basin, with the rate increasing eastward away from the predicted pole of rotation. We estimate shortening from north-south multichannel seismic profiles described by Bull and Scrutton [1990a] to be 1.2 

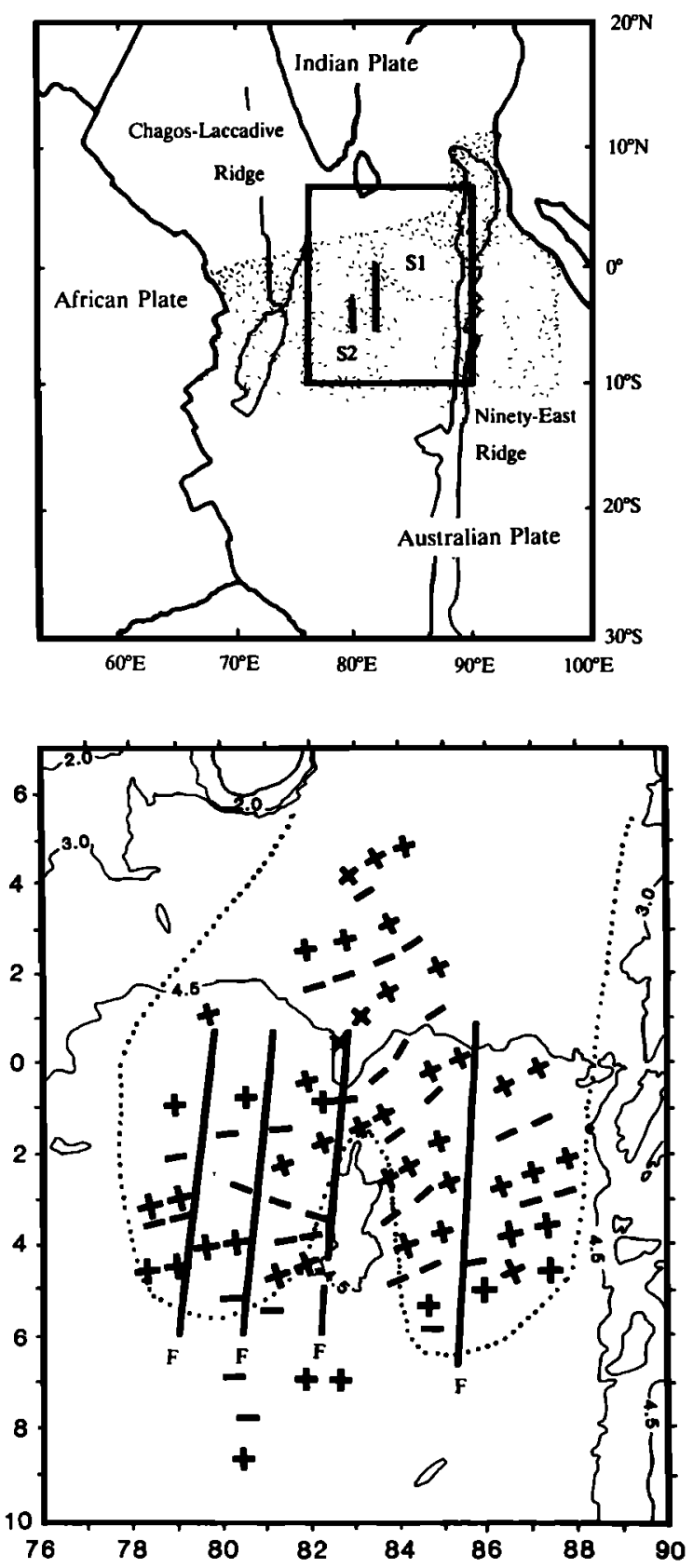

Fig. 1. Location of the intraplate deformation in the central Indian Ocean basin. (Top) The diffuse plate boundary (stipple pattern) separates the Indian and Australian plates [after Stein et al., 1989]. The positions of two profiles discussed within this paper are shown as lines S1 and S2. The open rectangle shows an area of the intraplate deformation studied in detail below. (Bottom) Acoustic basement highs and lows are from Geller et al. [1983] and Bull [1990a] with plus signs representing basement highs and minus signs relative lows. Note that in many areas the undulations are clearly discontinuous across fracture zones (denoted by solid lines striking $10^{\circ} \mathrm{N}$ and marked F). The dotted line shows the approximate limit of the Bengal Fan. Also shown are bathymetric contours in kilometers.
$(+0.4) \%$. For the approximate $1500 \mathrm{~km}$ north-south extent of the deformation this corresponds to a total shortening of $18( \pm 6) \mathrm{km}$. If deformation is assumed to have started at $7 \mathrm{Ma}$ and to have been steady to the present, this implies a shortening rate of $2.5( \pm 0.9) \mathrm{mm}$ $\mathrm{yr}^{-1}$. This rate is toward the lower end of plate motion predictions but rather more than a previous estimate made from single channel profiles of $\sim 1 \mathrm{~mm} \mathrm{yr}^{-1}$ [Weissel and Geller, 1981].

Other observational evidence for the mode of formation of the long wavelength is contradictory. Two recent refraction studies made diametrically opposing conclusions on crustal thickness: Leger [1989] found that $30 \%$ crustal thickening was present beneath a prominent undulation crest indicating inverse boudinage, while Neprochnov et al. [1988], as part of a larger study, found that under the same crest visited by Leger [1989], the crust was thinner, relative to other parts of the central Indian Ocean basin. The only multichannel seismic profiles over the deformation area [Bull and Scrutton, 1990a], while resolving reverse faults to around the expected level of the oceanic Moho, do not image the latter convincingly and therefore give no direct information on the mode of formation of the long-wavelength undulations.

Leger and Louden [1990] use a simple argument based on the amplitude of Seasat-derived gravity anomalies to argue for crustal thickening under the crest investigated by their seismic refraction experiment, and hence support the inverse boudinage hypothesis. The essence of their argument is that the amplitude of the gravity anomalies ( -25 to $-35 \mathrm{mGal}$ peak to trough from the satellite data) is too small for the buckling hypothesis. However, shipcollected gravity data over the same crest (Figure 3 ) show a peak to trough amplitude of $\sim 50 \mathrm{mGals}$. Clearly, reduction of altimetry data (by the Haxby method at least) loses high frequency components. In particular, it underestimates crestal gravity values by $\sim 15 \mathrm{mGals}$. Twodimensional gravity modeling using ship-collected data (confirmed by three-dimensional modeling by Bull [1990b]) with a uniformly folded $5 \mathrm{~km}$ thick crust over the same crest (Figure 3) gives a convincing fit to the observed data. Inverse boudinage (here for $\sim 30 \%$ thickening) gives insufficient amplitude. The authors would like to point out that this relation is certainly not as clear throughout the deformation area and that the situation is additionally complicated by poor knowledge of density variations within the sedimentary column.

In summary, observations give rise to mechanical approaches that try to characterize the periodic instabilities and to relate them to the oceanic lithosphere rheology. The purpose of this study is to use the sandbox technique [Davy, 1986; Davy and Cobbold, 1991] to study lithosphere rheology under compression and determine the mode of deformation. If the mode of formation of the long-wavelength undulations could be determined this would give important information on the manner in which the oceanic lithosphere responds to long-term horizontal compressive stress.

\section{PERIODIC INSTABILITIES IN THE OCEANIC LITHOSPHERE}

Periodic instabilities can be generated within various kinds of rheologies (from elastic to Newtonian viscous). 
a

b

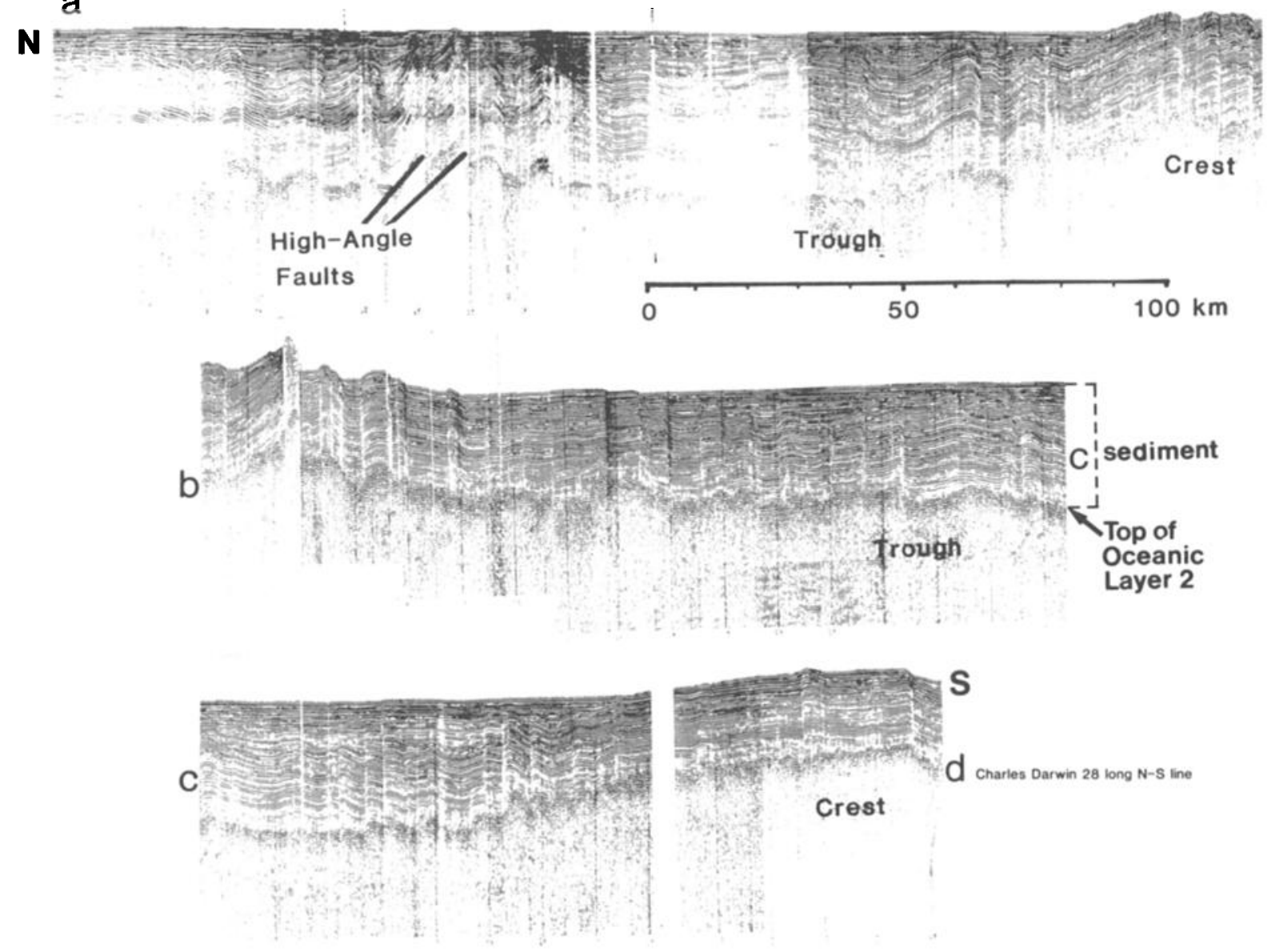

Fig. 2. Continuous north-south seismic profile (along $81.5^{\circ} \mathrm{E}, 0.5-5.0^{\circ} \mathrm{S}$; line $\mathrm{S} 1$ in Figure 1) showing the two spatial scales of the deformation: the long-wavelength $(150-200 \mathrm{~km})$ undulations of oceanic basement and overlying sediments; and the high-angle faults and associated folds. Sedimentary thickness decreases with increasing distance from the sources of the Bengal Fan: from approximately $2.3 \mathrm{~km}$ at the northern end of the profile to $0.9 \mathrm{~km}$ at the southern end. (Thicknesses were calculated using velocities from Bull and Scrutton [1990b]).

We first review the models of lithospheric rheologies already in the literature and the resulting instabilites expected.

At low stress, most rocks behave elastically. This behavior breaks down at low temperature into fracture with a remarkable universal depth-dependent yield strength [see Byerlee, 1978] and at high temperature into a ductile creep behavior [see Goetze and Evans, 1979]. As emphasized below, each of these three behaviors can generate periodic instabilities.

Compressive periodic instability for an elastic plate with a free surface is buckling [see Turcotte and Schubert, 1982]. However, elastic parameters deduced from flexural studies [Watts, 1978; McNutt and Menard, 1982] or from wavelength observations (see Weissel et al. [1980] for their study on the central Indian Ocean) predict that compressive stresses larger than the failure stress limit are needed. That is, the oceanic plate would fail by fracturing before buckling.

It is clear that a purely elastic theological model for the oceanic lithosphere is too simplistic. An alternative model is to consider the lithosphere divided into three rheological regions: an upper brittle layer, with failure stress increasing with depth; a lower ductile region, in which the yield stress decreases exponentially with increasing depth and temperature, and an elastic core between these two layers [see Goetze and Evans, 1979]. It is not surprising that the layered rheological models that use this yield stress envelope [McAdoo et al., 1985; Bodine et al., 1981] achieve a better fit for the bathymetry and gravity of outer rise trench systems. McAdoo and Sandwell [1985] argue that with thinning of the elastic core due to yielding at the top and bottom of a horizontally compressed lithosphere, the lithosphere buckles prior to whole lithospheric failure. This explanation seems sensible as all rocks deform elastically before permanent deformation (that is, brittle, semi-brittle or viscous) processes are activated. An elastic core is certainly maintained during the first stages of compression, when compressive stresses are still weak. This core is situated in the stronger part of the lithosphere which occurs at mid-lithosphere depths. The question is, does this elastic core still exist in the deformed Indian 


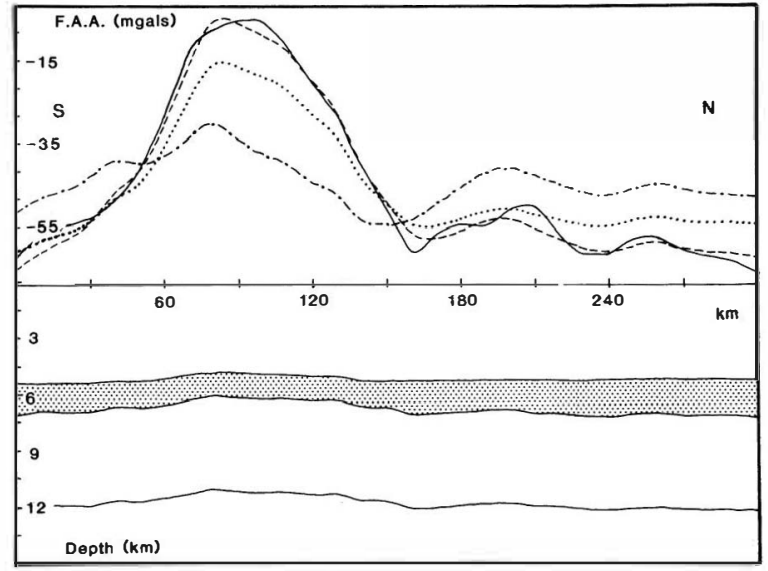

Fig. 3. Two-dimensional gravity modeling for line S2 (see Figure 1). Densities for water, sediment, crust, and mantle are $1030,2200,2800$ and $3300 \mathrm{~kg} \mathrm{~m}^{-3}$ respectively. Stippled area indicates the sedimentary layer. The continuous line is the observed Free-Air anomaly (FAA), and the dashed line is the anomaly produced by the underlying model which has a uniform $5.0 \mathrm{~km}$ thick crust. The dotted line shows the anomaly for a flat Moho, while the dot-dashed line is the anomaly for $30 \%$ thickening under the basement crest. Depth conversion was completed using velocities from Bull and Scrutton [1990b].

Ocean lithosphere? We do not believe so, and we think that the development of instabilities is controlled $b_{; j}$ the permanent deformation processes of the lithosphere.

Applied to the intraplate deformation in the central Indian Ocean basin, the McAdoo and Sandwell model, using a slightly lower average lithospheric age (55 Ma) than we use $(65 \mathrm{Ma})$, predicts a wavelength of the right order, 160-240 km (Figure 4) with reasonable average compressive stresses of about $600 \mathrm{MPa}$. Such a stress level has been estimated by Cloetingh and Wortel [1986] with finite element calculations describing an elastic Indian Ocean plate and its boundaries.

However, the mechanical assumptions of the McAdoo and Sandwell model are disputable (see Martinod [1991] and Martinod and Davy [1992] for a longer discussion). The main criticism is that they assume that the stresses applied to the entire lithosphere are entirely redistributed in the elastic core although it represents less than $20 \%$ of the lithosphere thickness. In addition, they neglect the role of plastic (that is, permanent) deformation in the model.

In fact, plastic deformation processes appear to be very efficient in producing periodic instabilities. Most plastic models have studied the behavior of power law ductile flows where the strain-rate is proportional to $\tau^{n}$, where $\tau$ is the deviatoric stress and $\mathbf{n}$ is the exponent of the power law, the limit of $\mathbf{n}$ at infinity being a good representation of a purely plastic material with a yield stress (see Fletcher and Hallet [1983], Ricard and Froidevaux [1986], Zuber et al. [1986], Zuber [1987], Bassi and Bonnin [1988] and a complete review and criticisms by Martinod and Davy [1992]). The greater the value of $n$, the more unstable the material is with respect to periodic instabilities. Therefore, the driving role is given to the

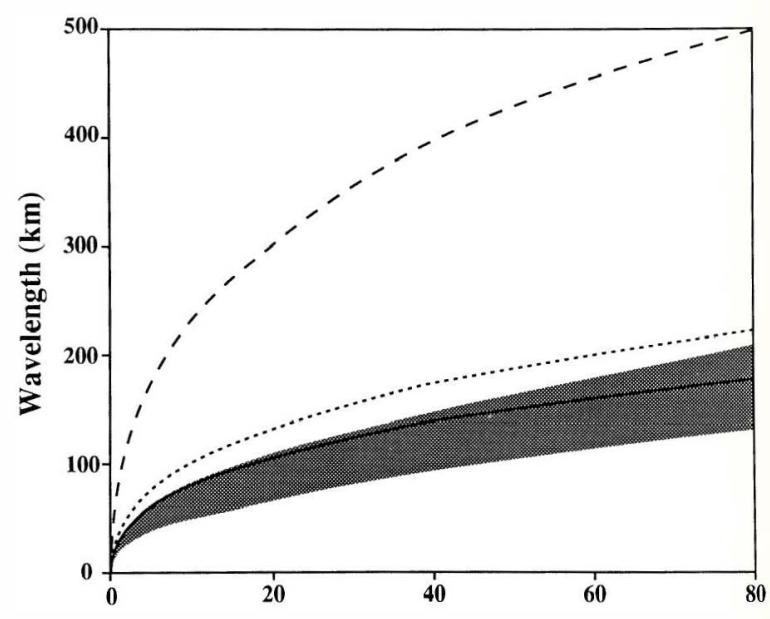

Age (Ma)

Fig. 4. Buckling wavelength in kilometers versus age for various models of the oceanic lithosphere. The elastic-plastic model of McAdoo and Sandwell [1985] is shown with (dotted curve) and without (solid curve) sediment loading. The shaded area shows the range of values predicted by the visco-plastic model (shaded area) of Martinod [1991] without sediments. A purely elastic lithosphere model (dashed line) predicts wavelengths much greater than those observed in the Indian Ocean.

upper brittle layer, which can be viewed as a purely plastic material (n equal to infinity).

In compression, the periodic instability predicted by this plastic model is buckling. Zuber [1987] proposed that inverse boudinage could also develop. This latter mechanism fits well the wavelength observed in the Indian Ocean but is obtained for unrealistic models of the rheology of the oceanic lithosphere. In one model, she considers the oceanic lithosphere to be entirely made of Newtonian viscous rocks. It is obviously not the case in nature. Furthermore, Martinod and Davy [1992] show that periodic instabilities developing during the compression of the lithosphere are controlled by the brittle layers of the lithosphere, and so this case is not considered here. In a second model, Zuber [1987] considers the lithosphere as a strong plastic layer floating on soft Newtonian asthenosphere. This model predicts that the compression of this model gives birth to the development of a shortwavelength inverse boudinage, which is not consistent with observations available in the area, except if the lithosphere is supposed to be very thick (more than $50 \mathrm{~km}$ ). The reasons for obtaining this last result are not clearly explained. The inhibition of the short-wavelength instabilities by the strong viscous layer present at the base of the lithosphere was certainly missed (see Martinod [1991] and Martinod and Davy [1992] for a longer discussion).

Calculations for infinitesimal perturbations predict a ratio between the most probable wavelength $(\mathrm{L})$ and the thickness of the plastic layer (h1) of 4 . This ratio increases with the introduction of gravity effects or adding more stable layers, but the departure from the value of 4 remains small for reasonable parameters [see Martinod 
and Davy, 1992]. A major difference between plastic and elastic-plastic models is that a range of wavelengths can be amplified, with preferential selection of the wavelength with the largest calculated amplification rate. For comparison, the elastic-plastic model of McAdoo and Sandwell [1985] predicts a ratio $\mathbf{L} / \mathbf{h} 1$ slightly varying as $\mathrm{h}^{-1 / 4}$. With reasonable parameters, the estimated ratio for 65 Ma Indian plate is between 4.1 and 4.7 [Martinod and Davy, 1992].

Using values calculated from the plastic model, Martinod and Davy [1992] find a relationship between age and wavelength as shown in Figure 4. For the age of lithosphere in the central Indian Ocean basin (55-80 Ma) wavelengths between 135 and $210 \mathrm{~km}$ are predicted. These are consistent with observations, but with a lower average value.

These mechanical results are obtained from simplifications of the mechanical equations. The main reasons for these simplifications are the highly non-linear form of the basic rheological equations including, at worst, the stress drop linked to faulting. Thus these results deserve to be tested by experiments using properly scaled materials. Moreover, some questions remain as to the nature of the instability, the method of amplification, and the relationship to faulting.

\section{OCEANIC LITHOSPHERE RHEOLOGY AND THE SCALING OF THE ANALOGUE SYSTEMS}

For an experiment to be appropriate for a natural system requires a good knowledge of this system. Thus we briefly review the oceanic lithosphere rheologies.

\section{Oceanic Rheologies}

In recent years a wealth of results have been published from experimental work on the determinations of the frictional, fracture, and flow properties of peridotite and olivine, which are the dominant rock and mineral phase, respectively, of the upper mantle (see Kirby [1983] and Kirby and Kronenberg [1987] for reviews). In simplest terms, the brittle behaviour of the upper lithosphere may be described by a Mohr-Coulomb law. At depths greater than $4 \mathrm{~km}$, the relation obtained in laboratory studies by Byerlee [1978] for fracture and frictional sliding along preexisting weaknesses is

$\tau=50 \mathrm{MPa}+0.6\left(\sigma-\mathrm{P}_{\mathrm{t}}\right)$

where $\tau, \sigma$, and $P_{t}$ are, respectively, the shear component of the stress tensor, the normal component of the stress tensor, and the fluid pressure; they are expressed in megaPascals. As $\sigma$ increases with lithostatic pressure, the stress difference necessary to deform the upper brittle layer increases linearly with depth. Notice also that the cohesion is small compared to the average level of stresses.

The Byerlee relation may not be valid at great depths where the shear stress necessary for failure may become depth independent [see Ord and Hobbs, 1989]. The transition between these two deformation mechanisms could occur at a temperature of about $300^{\circ} \mathrm{C}$ (corresponding to depths around $10-15 \mathrm{~km}$ ), but it is far from being clearly identified. Additionally, it should be noted that the presence of fluid at depth within the oceanic crust may lead to significant reductions in strength within the brittle field. Confirmation of reaching the brittle yield strength in the central Indian Ocean basin, is shown by the recognition of faults penetrating throughout the oceanic crust and probably into the uppermost mantle [Bull and Scrutton, 1990a].

Brittle behavior is unlikely to extend to the lower parts of the lithosphere where, at higher temperatures, ductile creep predominates. Flow laws of olivine can be expressed as a power law relating strain rate and deviatoric stress at the power $n$, where $n$ is about 3 [e.g., Carter and Tsenn, 1987]. The flow law is highly temperature dependent and, for reasonable strain rates of $10^{-16}$ to $10^{-14} \mathrm{~s}^{-1}$, the strength supported by the ductile layer is 5 to 7 times less than that of the upper brittle layer [Davy and Cobbold, 1991].

As was emphasized in the previous paragraph, the determination of the thickness of the layers (especially the brittle layer which may control the wavelengths) is important. The brittle-ductile transition is usually found to be the depth where the positive-depth-dependent stress of the brittle layer is equal to the negative-depth-dependent stress of the ductile layer. Because of the temperature dependence of the ductile layers, the brittle-ductile transition is highly dependent on the thermal state of the lithosphere.

In the central Indian Ocean basin, which contains lithosphere of $55-80 \mathrm{Ma}$, a heat flux of $60( \pm 5) \mathrm{mW} \mathrm{m}^{-2}$ is the theoretical value expected. Stein and Weissel [1990] concluded that, despite the presence of localized heat flow anomalies, on the basis of the absence of a bathymetric anomaly and the presence of deep seismicity, lithospheric temperatures in the central Indian Ocean basin are not significantly different from those expected for its age.

The principal error in the calculation of the depth to the brittle-ductile transition comes from the uncertainty in the value of thermal conductivity $\mathbf{k}$, whose range lies between 2.5 and $4.0 \mathrm{~W} \mathrm{~m}^{-1} \mathrm{~K}^{-1}$. For this reason, a depth range of $25-50 \mathrm{~km}$ was found (by assuming a linear temperature gradient with a surface heat flux of $\left.60( \pm 5) \mathrm{mW} \mathrm{m}^{-2}\right)$; this range includes the departure from Byerlee's law discussed above. Studies of the distribution of seismicity with depth indicate a depth around $30( \pm 10) \mathrm{km}$ for the base of the seismogenic layer [Bergman and Solomon, 1985]. If that depth can be evaluated as the brittle-ductile transition (see comments by Ord and Hobbs [1989]), this gives a more reasonable range than that obtained from thermal arguments.

\section{Analogue Materials Rheology and Scaling}

The experimental technique that we used is especially relevant to the study of the brittle-ductile interactions with correct gravity forces. Our "lithosphere" is made of dry sand and silicone putty resting on a heavy weak "asthenospheric" syrup. The relevence of this rheological model of the lithosphere and its correct representation by analogue materials is widely discussed by Davy and Cobbold [1991] and Davy [1986]. We summarize only the important points in the following section.

First, as gravitational forces play a very important role in the development of instabilities, analogue materials are 
chosen to be correctly scaled for gravity. The "brittle" upper layer is made of dry sand which has a MohrCoulomb yield strength with no cohesion and angle of internal friction of about $30^{\circ}$. It is also characterized by a stress drop accompanying the formation of faults. In dry sand, internal deformation never exceeds $10 \%$ except in faults where a reorganization of sand grains with dilatancy ensures large strains. Density of dry sand is about $1400 \mathrm{~kg}$ $\mathbf{m}^{-3}$.

The ductile layer is made of silicone putty (Gomme 7007, manufactured by Rhone-Poulenc, France) which is a Newtonian viscous material with a viscosity that we can vary between $1.5 \times 10^{4}$ and $20 \times 10^{4} \mathrm{~Pa}$ s. A viscosity of $3 \times 10^{4}$ $\mathrm{Pa} s$ and a density of $1360-1380 \mathrm{~kg} \mathrm{~m}^{-3}$ were used in the experiments described here. Compared to the creep law of olivine, the rheology of the silicone putty can be expressed as a power law but with an exponent of 1 and no depth dependence. We have tested the differences introduced by the experimental technique with the analytical method described in the previous section (see for example, Ricard and Froidevaux [1986] and Martinod and Davy [1992]). We find that neither the difference in the exponent of the power law creep (in the range of 1 to 3 ) nor the depth dependence of the strength profile affect the results. The main reason is that the development of the instabilities is predominately controlled by the "brittle" upper layer. Underlying these two layers we used either pure Acacia honey or dense water (both with density $1400 \mathrm{~kg} \mathrm{~m}^{-3}$ ), to represent the viscous asthenosphere and to give isostatic support.

The scaling between the oceanic lithosphere and an analogue experiment is obtained by keeping the average resistance of the ductile layer correctly scaled with respect

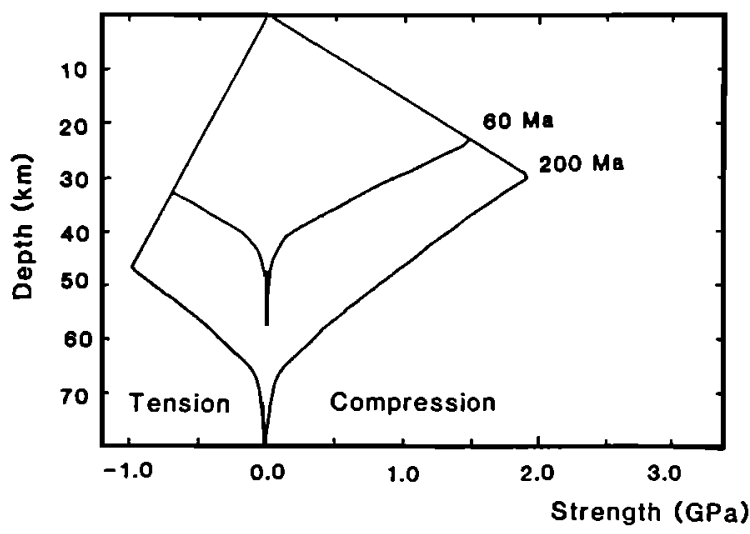

Fig. 5. Typical yield strength envelopes for the oceanic lithosphere for two different ages. Envelopes are based on the experimental work of Goetze and Evans [1979] and Brace and Kohlstedt [1980]. to the resistance of the upper brittle layer and to the gravity forces (see Davy and Cobbold [1991] for more details).

An example of a typical strength profile for the oceanic lithosphere is given in Figure 5. The validity of the scaling used in models is shown in Table 1 , where all dimensionless parameters are similar in nature and in the analogue experiments.

\section{EXPERIMENTAL DESIGN AND METHODOLOGY}

The three-layer model was placed in a sandbox with piston and motor as shown in Figure 6. A laser ranging device was used to measure the amplitude of the topography developed in the model by moving longitudinally at a constant height (usually $30 \mathrm{~cm}$ above the model). These were the first experiments to be run in Rennes using a laser, and controlling software was developed during the course of the experiments. For this reason, no laser profiles are available for the first experiment, and the results are poor for the next two. A camera was also placed above the model to photograph changes in a grid of white plastic powder (ethyl cellulose) on the top of each model.

Before the piston was started, the initial topography was measured several times using the laser so that the final profiles could be corrected for any preexisting topography. A constant compressive strain rate could then be applied through the model by the piston. Although the piston applied compression to the whole side of the model, the presence of holes in the lower part of the piston meant that the asthenospheric layer (honey/dense water) was only weakly stressed. Initially, identical models were run using different strain rates; strain rate was varied by using different motor speeds. The topography developed was the same in all experiments, and hence we had verified that the deformation was independent of strain rate.

Clearly, only realistic amounts of shortening should be allowed in the model. There is some discussion as to the amount of shortening that has taken place during the deformation in the Central Indian Ocean Basin as discussed earlier. However, it is clear that for realistic modeling we should focus on the topography and deformation that developed for the first few percent horizontal shortening.

In total, eight successful experiments were run, using a variety of brittle layer thicknesses and box widths. The topography developed was measured by the laser at regular periods (usually every 2 to $3 \mathrm{~min}$ ) during compression for experiments 2 to 8 . The laser moved across the model with velocity $0.02 \mathrm{~m} \mathrm{~s}^{-1}$, which for an average model length of $45 \mathrm{~cm}$ meant a profile could be recorded in $22 \mathrm{~s}$. This time to collect a profile is relatively small compared to the length of the experiment (up to 60 min), and therefore little distortion should be introduced

TABLE 1. Scaling of Natural and Analogue Systems

\begin{tabular}{lccccccc}
\hline System & $\mathrm{L}, \mathrm{m}$ & $\mathrm{t}, \mathrm{s}$ & $\sigma, \mathrm{Pa}$ & $\rho, \mathrm{kg} \mathrm{m}^{-3}$ & $\mu, \mathrm{Pa} \mathrm{s}$ & $\rho g L / \sigma$ & $\rho g L t / \mu$ \\
\hline Natural & $3.10^{4}$ & $10^{16}$ & $10^{9}$ & 3300 & $10^{22}$ & 1 & $10^{3}$ \\
Analogue & $2.10^{-2}$ & $10^{5}$ & 280 & 1400 & $3.10^{4}$ & 1 & $10^{3}$ \\
\hline
\end{tabular}




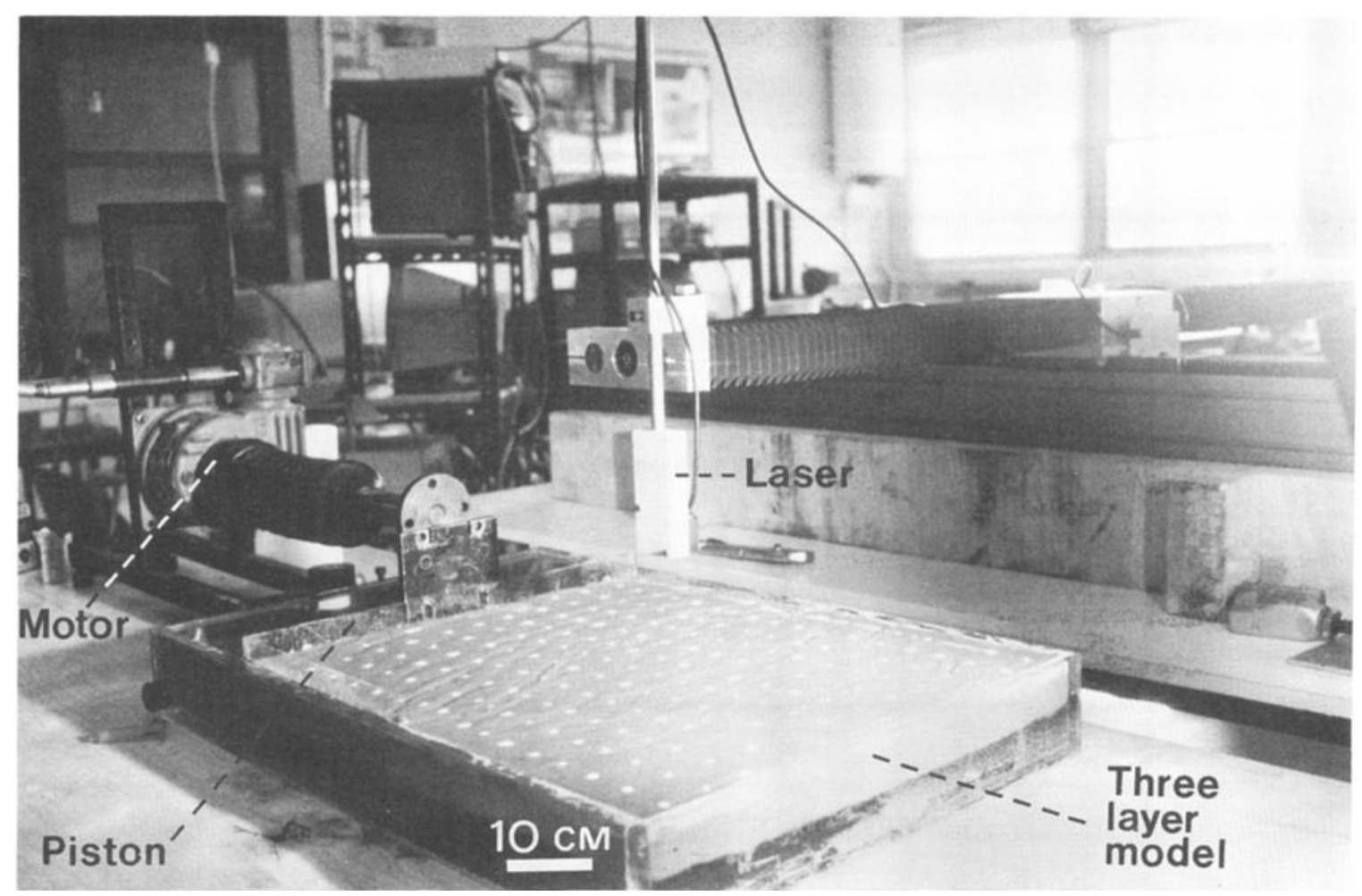

Fig. 6. Experimental apparatus. The three-layer model (sand, silicone, and honey/heavy water) is placed in a plastic box, toward one end of which is a piston that is driven, at a constant rate, by a motor. Above the model are a laser ranging device and camera (not shown) which record the topography developed throughout the experiment. A regular grid of white dots (ethyl cellulose) was placed on the top of the model to aid photographic analysis.

into the profile due to the finite time taken to complete a laser profile.

Following the experiment the initial topography was removed from all the measured profiles. Spectral analysis was then undertaken on these corrected profiles to determine the principal wavelengths present. The wavelength was estimated purely from photographs for experiment 1 , and from both photographs and spectral analyses for experiments 2 and 3 . Laser profiles were sufficiently good for experiments 4 to 8 that wavelengths were taken from the spectral analyses, although the corresponding photographs were checked for corroboration.

In experiments where dense water was used for the asthenosphere, the model was frozen after completion. When completely frozen these models were sawn into longitudinal sections, which were perpendicular to the fold axes, to determine the mode of deformation in the model.

\section{RESULTS}

In all the experiments, clear undulations could be observed in the top of the brittle layer before the appearance of the first reverse faults. Longitudinal sections of the models (Figure 7), after the end of compression and for reasonable amounts of shortening ( $<5 \%$ ), show that these undulations are the result of buckling of the whole thickness of the brittle layer. The ductile part of the model accommodates the buckling only in the upper domain, and the silicone/dense water interface does not show any vertical deformation.

The appearance and evolution of the surface undulations have been recorded using the laser (Figure 8). The topography of the models has been registered only on cross sections parallel to the direction of compression and situated in the middle of the box. These cross sections are representative of the deformation of the whole model because the undulations were linear and continuous along strike.

Spectral analyses of the successive topographies have been performed (Figures 9 and 10). They all show that, at least at the beginning of the appearance of vertical movements, only one wavelength is present. It is the wavelength of brittle layer buckling.

The results of the experiments and spectral analyses are given in Table 2. Listed for each experiment is the thickness of the brittle layer, buckling wavelength developed, and the ratio of buckling wavelength to brittle thickness. The ratio of buckling wavelength to brittle layer thickness (Table 2) ranges between 6.4 and 8.0 with an average value of 6.9 .

Observation of amplification of the undulations (Figure 8) leads to the conclusion that the positions of crests and troughs remain the same and therefore the wavelength is constant (at least up to $7.5 \%$ shortening). By analysis of spectral power of the main wavelength as a function of 


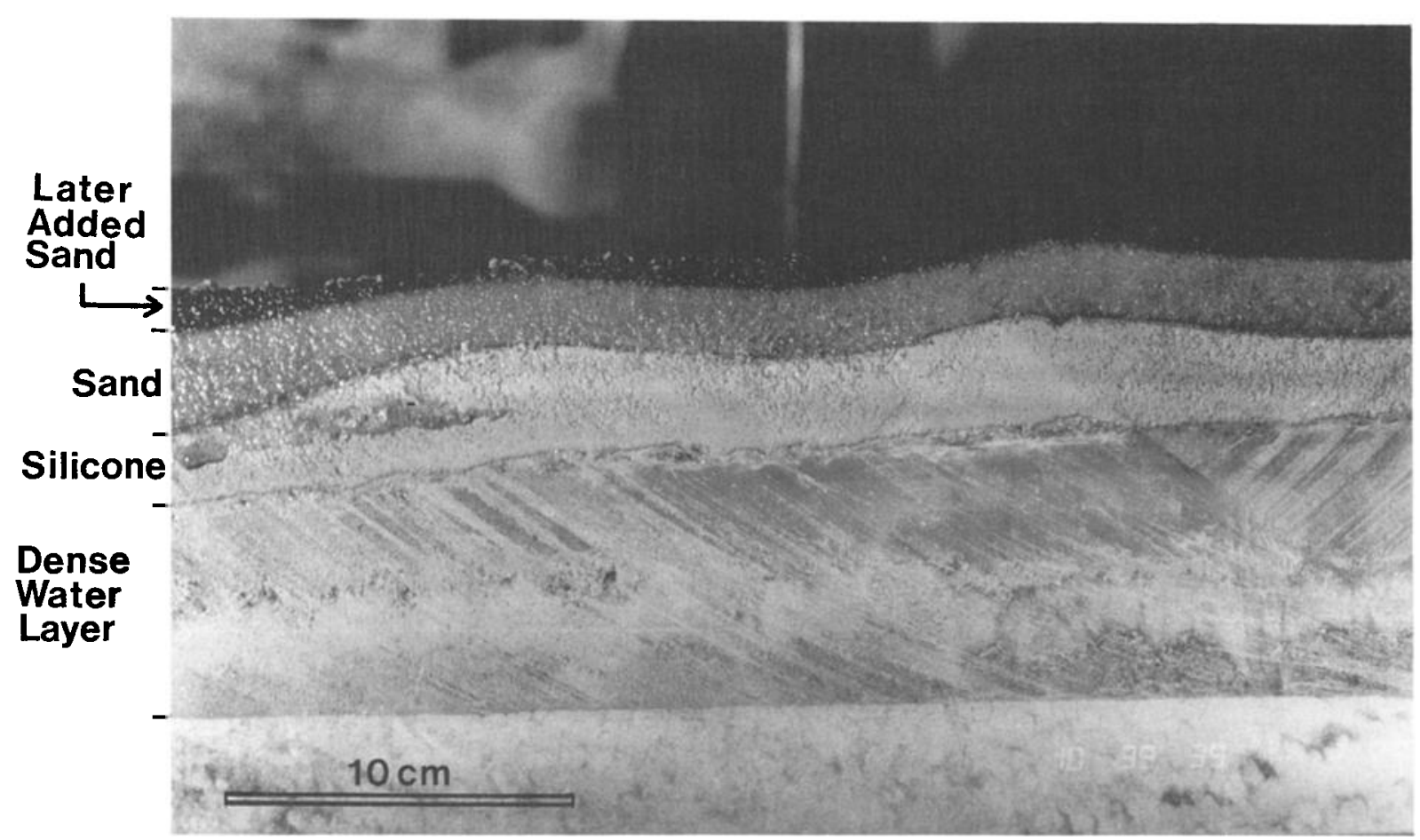

Fig. 7. Close-up of cross section produced by cutting a frozen model in half. The section shows uniform folding (buckling) of the brittle layer (grey sand). The black layer overlying the grey sand (brittle upper lithosphere) is additional sand which was carefully added to maintain the topography after the cessation of compression and prior to freezing. The lighter grey layer is made of viscous silicone, while the lowest layer is frozen dense water. The lines within the water layer are due to the circular saw. Note that there is no topography at the boundary between the silicone layer (viscous lower lithosphere) and the dense water layer (asthenosphere). In this model the brittle (sand) layer $(2 \mathrm{~cm})$ corresponds to $30 \mathrm{~km}$ in the natural system. The buckling wavelength (of $14.6 \mathrm{~cm}$ ) is hence $220 \mathrm{~km}$ and is $\sim 7$ times the thickness of the brittle layer.

time (Figure 11), it is possible to note that the amplification of the folds is exponential during the first stages of deformation. That is, for a few percent shortening, the relationship between spectral power and time in Figure 11 is a straight line. This can be compared to the theory developed by Biot [1961], Fletcher and Hallet [1983] and Ricard and Froidevaux [1986] for visco-plastic materials. This theory predicts that the small perturbations develop exponentially with respect to time and can be expressed as

$A(t)=A_{0} e^{q a t}$

where $A$ is the amplitude of the folds ( $A_{o}$ is the initial amplitude), $\dot{\epsilon}$ is the homogenous horizontal strain rate, and $q$ is the dimensionless growth rate factor of the deformation. Therefore the straight line in Figure 11 has a gradient equal to the product of the growth rate factor and the strain rate $(q \dot{\boldsymbol{q}})$. Although the parameters cannot be measured with much precision, for strain rates in the models of $\sim 5 \times 10^{-5}$, values of $q$ vary from experiment to experiment between $\mathbf{4 0}$ and 300 for the first few percent shortening. An average growth rate factor is about 100 . For high strains, analytic calculations are no longer valid, and in any case it is clear that folds cannot continue to grow exponentially with respect to time. The amplification rate of buckling decreases (in Figure 11, after 4\% shortening), and this generally corresponds with the appearance of the first faults in the model.

The amplitude-time relationship can be fitted by an exponential function as indicated by the log-normal plot of amplitude versus time (Figure 11). This exponential relationship verifies the one predicted by the plastic model (see section on periodic instabilities in the oceanic lithosphere and review by Martinod and Davy [1992]). The $q$ factors predicted by analytical calculations are around 400 and therefore are compatible with experimental results [Martinod and Davy, 1991].

\section{DISCUSSION: APPLICATION TO THE INDIAN OCEAN}

In the last section we noted that the buckling wavelength was approximately 7 times the thickness of the brittle layer. When rescaled to the natural system this result suggests that an oceanic lithosphere under compression with brittle thickness of $25-35 \mathrm{~km}$ will buckle with wavelength 190-240 km (from Table 2). 


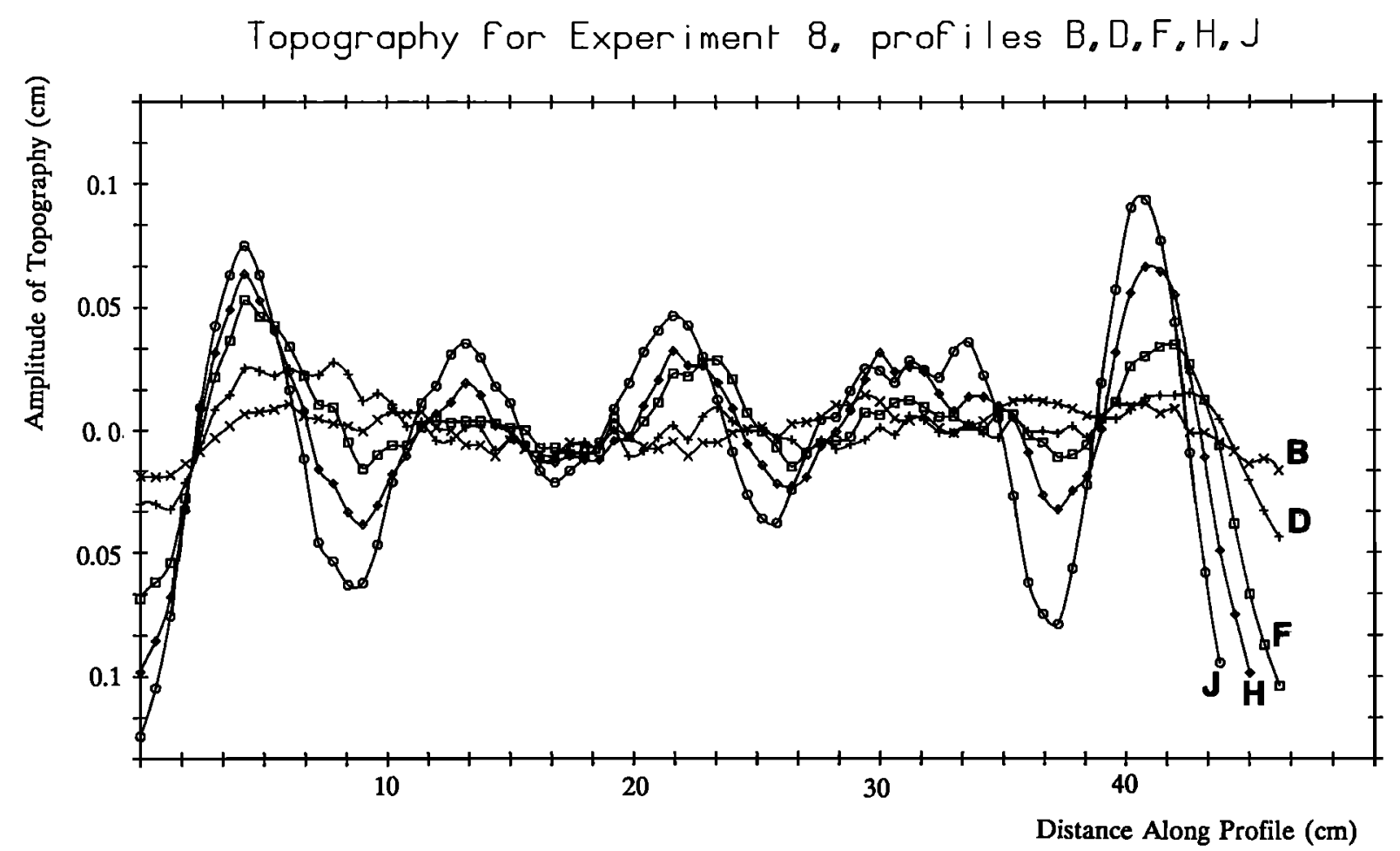

Fig. 8. Growth of folds in experiment 8 recorded by a laser at regular time intervals along a profile in the center of the model. All profiles have been corrected for any initial topography and rescaled. Note how the wavelength of folding is unchanged at $8 \mathrm{~cm}$ (or, rescaled, at 240 $\mathrm{km}$ ). The profiles shown here have been recorded after 1.5, 5.5, 10.5, 15.5, and $20.5 \mathrm{~min}$, which correspond to $0.3,1.4,2.7,4.0$, and $5.2 \%$ horizontal shortening, respectively.

One of the most characteristic features of the intraplate deformation in the Indian Ocean are the $\sim E-W$ trending geoid anomalies. Zuber [1987] analyzed these anomalies and found that the mean of the principal wavelength present ranged between $168.5 \mathrm{~km}$ and $222.3 \mathrm{~km}$, increasing to the north, as would be expected with increasing lithospheric age and increasing brittle layer thickness. The equivalent wavelengths obtained from the models (Table 2) are very similar, between $190 \mathrm{~km}$ and $240 \mathrm{~km}$. This agreement suggests that we have adequately modeled the oceanic lithosphere rheology with the simple two-layer model.

The observation of buckling (uniform layer thickness as opposed to variations predicted by the inverse boudinage model) in the analogue experiments gives strong support to the hypothesis of buckling for the mode of deformation of the oceanic lithosphere in the central Indian Ocean basin. It should be noted that we observe buckling of the whole of the model brittle layer. Because this layer, when rescaled, is $30( \pm 5) \mathrm{km}$ thick it implies that not only the crust but also a substantial amount of upper mantle is uniformly folded.

It is difficult to know the significance of the relationship between the brittle thickness and the wavelength of buckling. In the experiments, the buckling wavelength is $\sim 7$ times the brittle thickness. This contrasts with the predictions of 4 times the brittle thickness in the plastic model of Martinod and Davy [1992]. Reasons for this discrepancy are unclear; however, the physical models provide real observations, while the analytical solutions are only approximations.

With knowledge of growth rate in the experiments it is interesting to compare this to the natural system. If the initial perturbations were of the order of the amplitude of the predeformational abyssal hill topography, then an estimate of $100-200 \mathrm{~m}$ is reasonable for the initial perturbation [Bull and Scrutton, 1990b; Shipboard Scientific Party, 1989]. Amplitudes of folding observed in the Indian Ocean today range between 1 and $2 \mathrm{~km}$. By (2) this order of magnitude increase in amplitude gives

$\ln \left(A / A_{o}\right)=\ln (10)=q \dot{t} t$

which for a growth rate factor of 100 and a strain rate of $10^{-16} \mathrm{~s}^{-1}$ leads to a estimate of the time since the beginning of amplification of $\sim 7 \mathrm{~m}$.y. This result is now discussed.

With consideration of all the errors and assumptions involved, the finding of leg 116 [Shipboard Scientific Party, 1989] of 7 m.y. since the onset of deformation (from the unconformity between predeformational and syndeformational sediments) is probably coincidental. In fact, with the inclusion of sedimentation it would be expected that this time would be significantly reduced. However this agreement between observation and analysis of growth rate further supports the supposition that the models are accurate analogues of the natural system for a few percent shortening.

Beyond a few percent shortening the amplification of folds is no longer exponential and decreases rapidly. This 

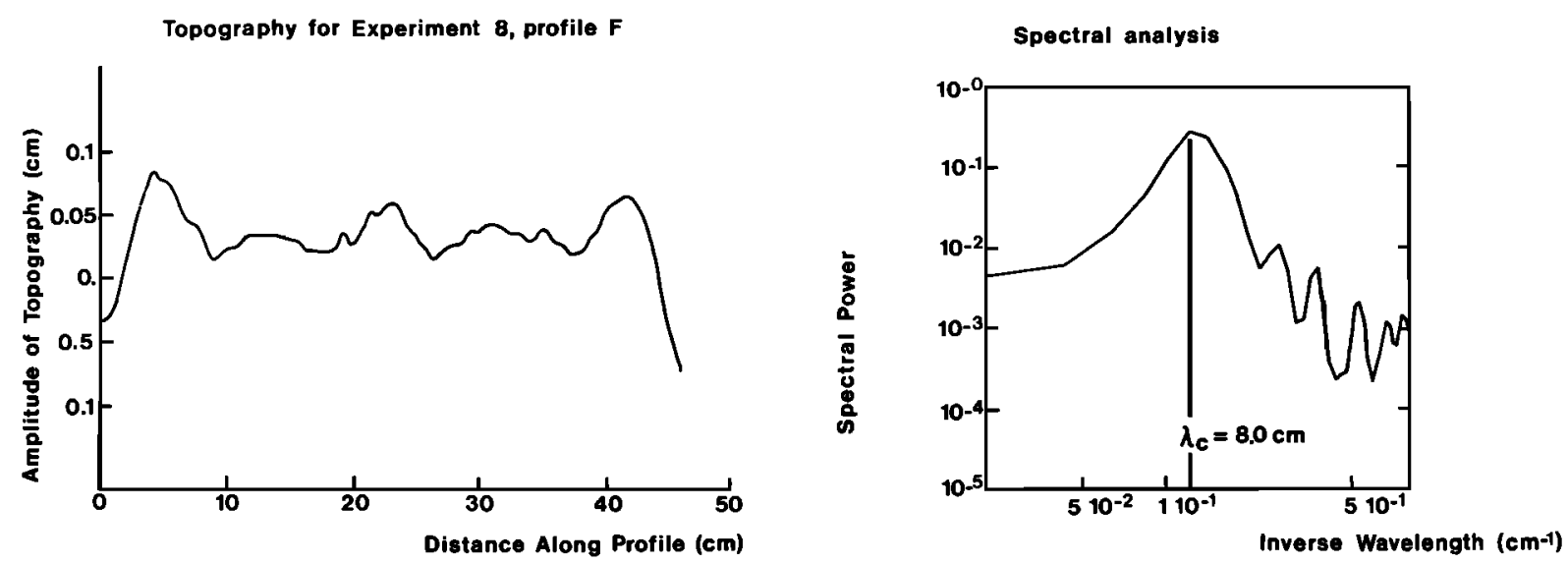

Fig. 9. Corrected topography and spectral analysis of experiment 8 for $2.7 \%$ shortening (profile F). A single dominant wavelength of folding is developed equal to $8 \mathrm{~cm}$ (or, rescaled, to 240 km). Five wavelengths of folding are present.
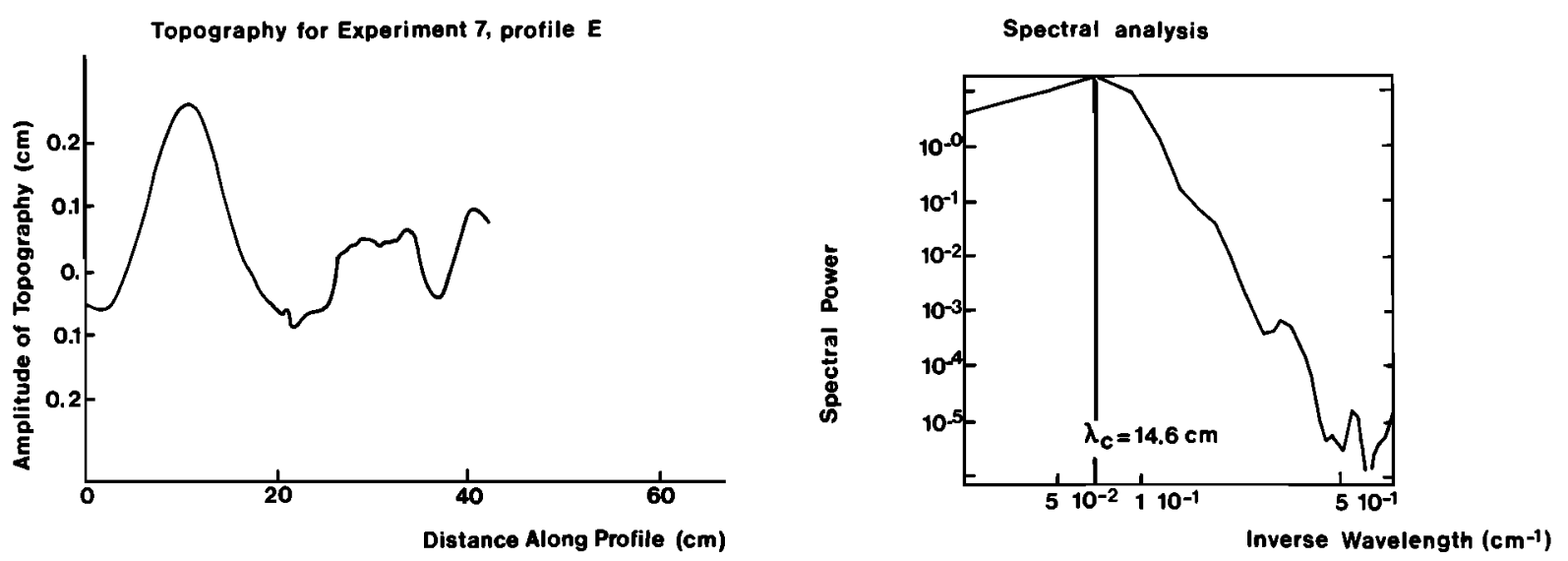

Fig. 10. Corrected topography and spectral analysis of experiment 7 for $2.8 \%$ percent shortening (profile E). A single dominant wavelength of folding is developed equal to $14.6 \mathrm{~cm}$ (or, rescaled, to $220 \mathrm{~km}$ ). Two to three wavelengths of folding are present in this experiment, which was undertaken in a box smaller than that for experiment 8.

is likely to be because further amplitude growth under the influence of gravity is energetically unfavorable. Instead, it is easier for the whole lithosphere to fail by reverse faulting. These faults generally develop at the inflection points of the undulations in the models.

Simplifications in the modeling procedure included the absence of sedimentation. If sedimentation had been included, it is likely that it would have speeded up the growth of the undulations and contributed to the accentuation of the crests relative to the troughs [Bull, 1990a]. Another simplification is the absence of a weak negative density gradient at the base of the lithosphere. In the models, for obvious practical reasons, it was necessary to build a lithosphere slightly less dense than the asthenosphere. This positive density contrast does not modify the early development of the instabilities: when the instabilities remain small, the lithosphere-asthenonsphere boundary is not affected by them, and it remains flat. However, this density contrast prevents the model
TABLE 2. Table of Experimental Results

\begin{tabular}{cccc}
\hline Experiment & h1, cm & L, cm & Ratio (L/h1) \\
\hline 1 & 2.0 & 13.5 & 6.7 \\
2 & 2.0 & 14.0 & 7.0 \\
3 & 2.0 & 12.6 & 6.3 \\
4 & 2.0 & 13.4 & 6.7 \\
5 & 2.0 & 12.8 & 6.4 \\
6 & 1.3 & 8.7 & 6.7 \\
7 & 2.0 & 14.6 & 7.3 \\
8 & 1.0 & 8.0 & 8.0 \\
\hline
\end{tabular}

h1 corresponds to the brittle layer thickness, and $\mathrm{L}$ is the buckling wavelength. 


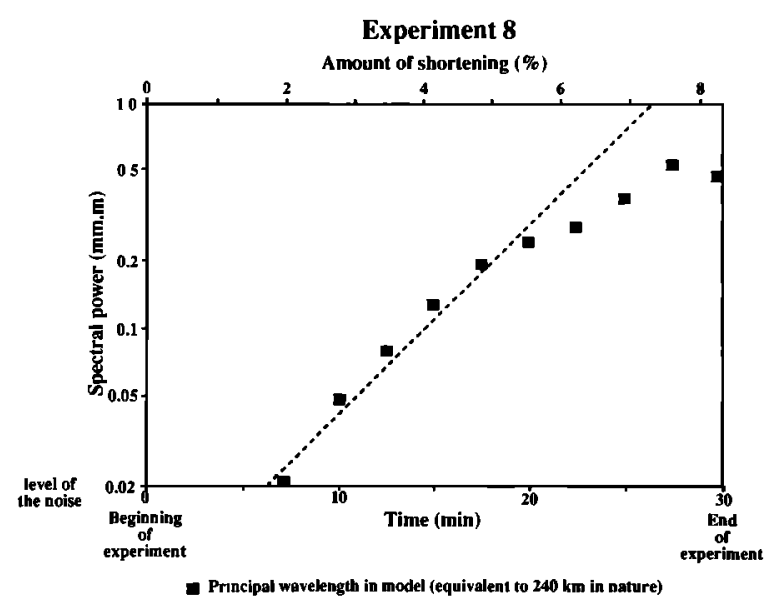

Fig. 11. Spectral power versus amount of shortening and time since the onset of deformation for the dominant wavelength present $(8 \mathrm{~cm}$ or, rescaled, to $240 \mathrm{~km}$; see Figures 8 and 9) in experiment 8 . For small amounts of shortening $(<4.7 \%)$ this $\log$-normal graph is a straight line suggesting exponential growth of the principal wavelength. Using visco-plastic theory, for a given strain rate in the model, a growth rate factor $q$ can be estimated. See text for discussion.

lithosphere from sinking into the model asthenosphere as might be observed after the appearance of faults that break the entire brittle domain. Thus subduction zones cannot occur in the models, as might be expected for large amounts of shortening and extreme buckling.

Although the analogue experiments successfully model the long-wavelength features, they are less satisfactory in modeling the shorter-wavelength features represented in the central Indian Ocean by reverse faulting and associated folds in the overlying cover. In the experiments, buckling (which starts at $\mathbf{1 . 0 \%}$ shortening) precedes faulting, and when detectable faulting occurs (after $\sim 5.0 \%$ shortening), it appears preferentially at the inflection points of the undulations. The appearance of faults at inflection points is not surprising, because at these positions the bending stress is a maximum. In the natural system, however, faults do not preferentially occur at the inflection points [Bull, 1990a], and motion along the faults appears to have been steady since the onset of deformation [Shipboard Scientific Party, 1989].

It is interesting to compare the shape of the undulations observed in the Indian Ocean with the shape of folds produced in the analogue experiments. As discussed briefly above, the undulations in the Indian Ocean tend to have broader troughs and sharper crests. The reason for this is likely to be a combination of the roles of faulting [Bull, 1990a] and sedimentation. In the analogue models we tend to observe symmetrical folds, and this we ascribe to the absence of modeled sedimentation and our failure to model the shorter-wavelength faults. Smith [1979] showed that, for compression of a non-Newtonian layer, tongues of incompetent material will sharpen and penetrate while the tongues of competent material will tend to broaden and retreat. This is the exact opposite of the trend observed in the Indian Ocean and thus we conclude that the presence of cusplike basement ridges pointing up into the weaker sediment layer in the Indian Ocean is unlikely to be produced by the amplification of instabilities (whether by buckling or inverse boudinage).

The question remains therefore as to the nature of the high-angle reverse faults at depth, and indeed the relationship between the faults and the long wavelength undulations in the Indian Ocean. As was mentioned previously, Bull [1990a] showed that faulting alone could not have generated the undulations. In this paper we have shown that buckling is the facilitating mechanism. We follow the argument of Bull and Scrutton [1990a] in suggesting that fault nucleation occurred at the brittleductile transition and propagated upward reactivating the original ridge-parallel fabric in the crust. Variations in the depth to the brittle-ductile transition and hence fault nucleation position, caused by brittle lithosphere buckling, may account for the accentuation of the crests of the undulations by the faults in the natural system.

\section{CONCLUSIONS}

The principal conclusions of the analogue modeling are the following.

1. Buckling is likely to be the mode of deformation in the central Indian Ocean basin, with the uniform folding of the whole of the brittle layer ( $30 \mathrm{~km}$ thick).

2. There is an association such that the buckling wavelength is typically 7 times the brittle layer thickness. The reasons for this association are poorly understood and are the subject of continuing work.

Acknowledgments. We would like to thank Peter Cobbold and Roger Scrutton for useful discussions. Some of the data analysis was completed when J.B. was supported by NERC grant GR3/6480 at the Department of Geology and Geophysics, Edinburgh University. J.M. and P.D. were supported by Institut National des Sciences de l'Univeis/Dynamique et Bilan de la Terre (instabilités). We would like to thank Rolf Meissner, Christopher Talbot, and an anonymous reviewer for constructive criticisms and suggestions.

\section{REFERENCES}

Bassı, G., and J. Bonnin, Rheological modelling and deformation instability of lithosphere under extension, Geophys. J., 93, 485-504, 1988.

Bergman, E.A., and S.C. Solomon, Earthquake source mechanisms from body wave inversion and intra-plate tectonics in the Northern Indian Ocean, Phys. Earth. Planet. Inter., 40, 1-23, 1985.
Biot, M.A., Theory of folding of stratified visco-elastic media and its implications in tectonics and orogenesis, Geol. Soc. Am. Bull, 72, 1595-1620, 1961.

Bodine, J.H., M.S. Steckler, and A.B. Watts, Observations of flexure and the rheology of the Oceanic lithosphere, J. Geophys. Res., 86, 3695-3707, 1981.

Brace, W. and D.L. Kohlstedt, Limits on lithospheric stress imposed by laboratory experiment, J. Geophys. Res., 85, 6248 - 6252, 1980.

Bull, J.M., Structural style of intraplate deformation, Central Indian Ocean Basin: evidence for the role of fracture zones, Tectonophysics, 184, 213-228, 1990a.

Bull, J.M., The structural style of intraplate deformation, Central Indian Ocean Basin, 
Ph.D. thesis, 218 pp, Univ. of Edinburgh, Edinburgh, United Kingdom, 1990b. Bull, J.M., and R.A. Scrutton, Fault reactivation in the Central Indian Ocean Basin and the rheology of the oceanic lithosphere, Nature, 344, 855-858, 1990a.

Bull, J.M. and R.A. Scrutton, Sediment velocities and deep structure from wideangle reflection data around ODP Leg 116 sites, Proc Ocean Drill. Program Sci. Results 116, 311-316, 1990 b.

Byerlee, J.D., Friction of Rocks, Pure Appl. Geophys., 116, 615-626, 1978.

Carter, N.L., and M. Tsenn, Flow properties of continental lithosphere, Tectonophysics, 136, 27-63, 1987.

Cloetingh, S., and R. Wortel, Stress in the Indo-Australian plate, Tectonophysics, 132, 49-67, 1986.

Curray, J.R, and T. Munasingbe, Timing of intraplate deformation, northeastern Indian Ocean, Earth Planet. Sci. Lett., 94, 71-77, 1989.

Davy, $\mathbf{P}$., Modélisation thermomécanique de la collision continentale, Mem. Doc. 8 , 233pp, Centre Armoricain d'Etude Structurale des Socles, Rennes, France, 1986.

Davy, P., and P.R. Cobbold, Experiments on shortening of a four layer model of the continental lithosphere, Tectonophysics, 188 1-26, 1991.

DeMets, C., R.G. Gordon, and D. Argus, Intraplate deformation and closure of the Australia-Antarctica-Africa Plate Circuit, $J$. Geophys. Res., 93, 11877-11897, 1988.

Fletcher, R.C., and B. Hallet, Unstable extension of the lithosphere: A mechanical model for Basin and Range Structure, $J$. Geophys. Res., 88, 7457-7466, 1983.

Geller, G.A., J.K. Weissel, and R.N.

Anderson, Heat transfer and intraplate deformation in the central Indian Ocean, $J$ Geophys. Res., 88, 1018-1032, 1983.

Goetze, C., and B. Evans, Stress and temperature in the bending lithosphere as constrained by experimental rock mechanics, Geophys. J. R Astron. Soc, 59, 463-478, 1979.

Gordon, R.G., C. DeMets, and D.F. Argus,

Present day motion between the Australian and Indian plates: kinematic constraints on distributed lithospheric deformation in the Equatorial Indian Ocean, Tectonics, 9, 409-423, 1990.

Kirby, S.H., Rheology of the lithosphere. Rev. Geophys., 21, 1458-1487, 1983.

Kirby, S.H., and A.K. Kronenberg, A.K. Rheology of the lithosphere: Selected topics. Rev. Geophys., 25, 1219-1244, 1987.
Leger, G.T., Was the oceanic crust in the Central Indian Basin deformed by lithospheric boudinage? Evidence from seismic refraction, M.Sc. thesis, Dalhousie Univ., Halifax, Nova Scotia, 1989.

Leger, G.T., and K.E. Louden, Seismic refraction measurements in the Central Indian Basin: evidence for crustal thickening related to intraplate deformation, Ocean Drill. Program, Sci. Results., 116, 291-309, 1990.

Martinod, J., Instabilités périodiques de la lithosphere (flambage, boudinage) en compression et en extension, Mém. Doc. 44, 182pp, Centre Armoricain d'Etude Structurale des Socles, Rennes, France, 1991.

Martinod, J., and P. Davy, Periodic Instabilities during compression or extension of the lithosphere: 1. Deformation modes from an analytical perturbation method, J. Geophys. Res., 97, 1999-2014, 1992

McAdoo, D.C., and D.T. Sandwell, Folding of the oceanic lithosphere, J. Geophys. Res., 90 , 8563-B569, 1985

McAdoo, D.C., C.F. Martin, and S. Poulouse, Seasat observations of flexure: evidence for a strong lithosphere, Tectonophysics, 116, 209-222, 1985.

McNutt M.K. and H.W. Menard, Constraints on yield strength in the oceanic lithosphere derived from observations of flexure, Geophys. J. R. Astron. Soc., 59, 363-394, 1982.

Neprochnov, Y.P., O.V. Levchenko, L.R. Merklin, and V.V. Sedov, The structure and tectonics of the intraplate deformation area in the Indian Ocean. Tectonophysics, 156, 89-106, 1988.

Ord, A., and B.E. Hobbs, The strength of the continental crust, detachment zones and the development of plastic instabilities, Tectonophysics, 158, 269-289, 1989.

Petroy, D.E, and D.A. Wiens, Historical seismicity and implications for diffuse plate convergence in the northeast Indian Ocean, J. Geophys. Res., 94, 12301-12319, 1989.

Ricard, Y., and C. Froidevaux, Stretching instabilities and lithospheric boudinage, $J$. Geophys. Res., 91, 8314-8324, 1986.

Royer, J.Y., and T. Chang, Evidence for relative motions between the Indian and Australian plates during the last $20 \mathrm{Myr}$ from plate tectonic reconstructions. Implications for the deformation of the Indo-Australian plate, J. Geophys. Res., 96, 11779-11802, 1991.

Shipboard Scientific Party, ODP Leg 116 site survey, Proc. Ocean Drill. Program Initial Rep., 116, 197-210, 1989.
Smilh, R.B., Formation of folds, boudinage and mullions in non Newtonian materials, Geol. Soc. Am. Bull., 88, 312-320, 1977.

Smith, RB., The folding of a strongly NonNewtonian layer, Am. J. Sci., 279, 272-287, 1979.

Stein, C. A., and J.K. Weissel, Constraints on Central Indian Ocean Basin thermal structure from heat flow, seismicity and bathymetry, Tectonophysics, 176, 315-332, 1990.

Stein, C. A., S. Cloetingh, and R. Wortel, Seasat-derived gravity constraints on stress and deformation in the northeastern Indian Ocean. Geophys. Res. Lett., 16, 823-826, 1989.

Stephenson, RA., and S. Cloetingh, Some examples and mechanical aspects of continental lithospheric folding Tectonophysics, 188, 1-26, 1991.

Turcotte, D.L., and G. Schubert, Geodynamics: Applications of Continuum Physics to Geological Problems, John Wiley, New York, 1982.

Watts, A.B., An analysis of isostasy in the worlds oceans 1. Hawaiian-Empero Seamount chain, J. Geophys. Res., 83 , 5989-6004, 1978.

Weissel, J.K., and C.A. Geller, Preliminary results of 1980 shipboard investigations of deformation of the Indo-Australian plate. I Seismic Reflection (abstract), Eos Trans. $A G U, 62,404,1981$.

Weissel, J.K., R.N. Anderson, and C.A. Geller Deformation of the Indo-Australian plate, Nature, 287, 284-291, 1980.

Zuber, M. T., Compression of the oceanic Ithosphere: An analysis of intraplate deformation in the Central Indian Basin, $J$. Geophys. Res. 92, 4817-4825, 1987.

Zuber, M.T., E.M. Parmentier, and R.C. Fletcher, Extension of continental lithosphere: A model for two scales of basin and range deformation. J. Geophys. Res., 91, 4826-4838, 1986.

J.M. Bull, Department of Geology, University of Southampton, Highfield, Southampton SO9 5NH, United Kingdom. P. Davy, Institut de Geologie, Campus de Beaulieu, Avenue du General Leclerc, 35042 Rennes Cedex, France.

J. Martinod, Laboratoire de Géophysique Interne et Tectonophysique, Observatoire de Grenoble, BP 53X, 38041 Grenoble Cedex, France.

(Received January 2, 1991; revised June 12, 1991; accepted November 13, 1991.) 